\title{
Contemporary Music and Its Challenges for Music Theory
}

\author{
${ }^{\otimes}$ Martin W. C. Link
}

\author{
Westfälische Wilhelms Universität Münster, Germany
}

Received: December 13, 2017. Revised: April 23, 2018. Accepted: June 10, 2018

\begin{abstract}
Contemporary music has found different ways in order to realize new methods of compositions in a process of indiviulazitation. Many of its phenomenons such as the abandonment of functional tonality have already been announced by composers such as Richard Wagner and during its development many scholars have come up with different systems in order to add something new to the existing material. The variety of new models such as the center tone-theory or open forms have a new challenge for music theory, which was used to give accurate definitions of a common denominator. This article wants to analyze those new methods and the importance to understand them in order to be able to give a clear analysis.
\end{abstract}

Keywords: Theory; Analysis; Wagner; Tonality

How to Cite: Link, M. W. C. (2018). Contemporary Music and Its Challenges for Music Theory. Harmonia: Journal of Arts Research And Education, 18(1), 39-44. doi:http:/ / dx.doi.org/10.15294/harmonia.v18i1.13686

\section{INTRODUCTION}

Contemporary music is not something completely new to our ears, unlike the German term "Neue Musik" suggests. This genre of music, which had its problems in establishing after 1945, has found its way to the most important concert halls of the world and developed into the maybe most multifaceted category the history of music has ever seen. Names like Olivier Messiaen, Karlheinz Stockhausen and Luciano Berio are only a few examples of the broad scale of composers and techniques, that contemporary music has brought to daylight. Except the establishment on the stages, there is also another challenge which contemporary music has to overcome - that of a discipline, which is maybe the oldest and most important in understanding the structure of music.

\section{METHOD}

To understand the theory and coherences of contemporary music, 5 analyses of the different theory conceptions were carried out. Therefore, a first look at the classical status of harmonic hierarchy was executed and its gradual transference to more complex structures. Finally, three different theory conceptions of contemporary music were analyzed as well and are demonstrated with the help of short illustrations to show their functionality and their new capacity in relation to classical theory.

\section{Analysis 1: Unambigious music theory in the past}

For centuries, music theory has been an important discipline to highlight structures and composition techniques of the great composers. A very famous term of this profession, which almost every music student has come across, is counterpoint. Among other fields, such as harmony teaching and morphology, counterpoint has developed into a scholarship, which investigates how the different parts of a fugue or a motet are put together and how special effects like the treatment of the harmo-

\footnotetext{
Corresponding author: Steinbeck 1a, Essen, 45239, Germany

E-mail: martinlink89@hotmail.com
} 
nic functions and dissonances have been executed. But music theory was not only the study of music of the past but also of music that is composed at the moment. Another task among historic study was therefore to set out rules, how music had to be put together properly. This led to very strict examples of musical law like four-part-writing with its prohibition of parallel fifths for instance (Figure 1).

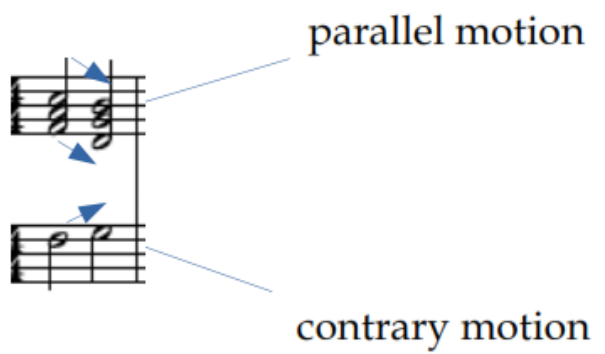

Figure 1. Four part-writing with 5th-parallel avoidance

The best proof of a strict and definite scholarship of music theory is maybe the publication Gradus ad parnassum by Austrian composer Johann Joseph Fux in 1725, which is still an essential Element of today's counterpoint teaching in the maybe most dogmatic sense. Theories like the fourt part-sentence in music were not rules that lasted for an eternity and didn't had a role like the law of grivity. But they reflect a momentum of music history, where a strict definition of reasonable music could be given and certain strategies of composing were simply inappropriate like the application of unresolved dissonances. This means on the one hand that at the time of J.J. Fux, it was quite possible to define well-sounding music. On the other hand, this leads us to the question why such restrictions were made at all and especially a musician of our time would wonder, why at those days sound material like certain dissonances were simply excluded. An easy answer could be that people during the time of Palestrina or Heinrich Schütz were not used to hear such "strange sounds" like unresolved dominant seventh chords or II-V-I-progressions and therefore, it would have sounded for them like a mispitched error, while today we can recognize such phenomenons as a natural part of our musical sourrounding.

However, we know that already musicians like Johann Sebastian Bach were about to break the dogmatic rules of proper harmony teaching. His technique of including complex harmonies in an interleaved pattern lead to the term of harmonic counterpoint, which defines the network of different harmonic functions related to each other and can be found even in only one part for instance in the arpeggios of the Cello Suite No. V BWV 1011. Another new feature of Bach is chromaticism, which means that the complete range of a scale-sector is used, like from a to g-sharp in the first bar of the prelude in Präludium \& Fuge a-moll BWV 889. Music theory teaching after Bach included his style of composing and rose chromaticism and harmonic counterpoint to a new dogmatic rule of how proper counterpoint-writing should be executed. In other words new complexity, which was unheard of at the time, was integrated and strange habits became a substantial part of musical structure. The maybe best example is the well known sixte ajoutée, which was a very odd habit of the addition of a sixth in a chord on the fourth degree. In 1722, Jean Philippe Rameau give this appearance a proper name and included it in his textbook Traité de l'Harmonie.

Crystallization and shifting of rules has been common practice of music theory since the ancient Greek and their first scale theory of the systema teleion. Despite the complex additions to the codex of music theory, every new phenomenon could be discribed exactly with one term and clear definition. Thus, the appearances in music until the 20th century were successfully added in the catalogue of styles and counterpoint practices. Contemporary music however, has a challenge in this perspective.

\section{Analysis 2: Wagner and the announce- ment of free tonality}

It is not easy to give an exact definition, when contemporary music started. Many scholars start calling music after 1945 contemporary but as we will see, one if its most prominent theoretical phenomenons started already many years earlier.

Richard Wagner composed an Opera in 1865 , where a strange seventh-chord of the secondary dominant is combined with a diminished fifth in the bass and a sixth as derivation to the seventh, which is resolved again to a dominant seventh-chord with a derivation to the fifth by a sharpened fourth. This chain of derivations leads to the phenomenon that despite the root positions of secondary dominant and dominant, the leading tones in both chords disguise the progressions and moreover, the long duration of the derivating tones, the sixth and the fourth, prevent an accurate comprehension of the proper seventh and fifth - they become 
an integral part of the chord itself.

Wagner's often discribed and analyzed Tristan-chord is an early example of a structure of music dissolving itself from the gravity of tonality. In other words: The system, which was well constructed by scholars like Gottfried Weber with his publication Versuch einer geordneten Tonkunst and Simon Sechter's fundamental bass-theory, is about to be left behind. Still, music has not arrived there yet in 1865, but Wagner's extensive application of chordderivations in altered chords and delayed resolutions are a premonition of what is about to happen.

Unlike the old situation in the time of composers like Bach, this time it won't be enough simply to include the new dissonancetreatments into our catalogue of harmony teaching, because now music is about to call into question the organization of its foundation: functional tonality.

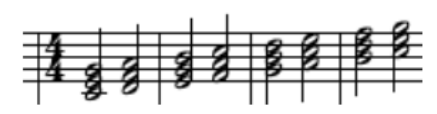

I II III IV V VI VII VIII

Figure 2. Scale degrees as the gravity of tonality.

The new changes of contemporary music, which have been announced in Wagner's opera Tristan und Isolde, are about to be so grave that in order to understand them, we have to develop new analytical tools in music theory.

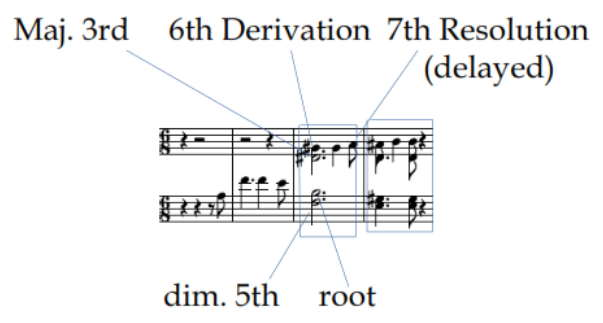

$\begin{array}{lll} & & 7 \\ \text { Chord: } & 67 & 4+5 \\ & \mathrm{~B} \Delta & \mathrm{E} \Delta \\ & 5^{\circ} & \\ & & \\ \text { Degree: } & \mathrm{V} / \mathrm{V} & \mathrm{V}\end{array}$

Figure 3. Tristan-chord with delayed resolution.

\section{Analysis 3: Vagierende Akkorde}

One of the first appearances of this new shift of gravity in contemporary music was in chord-structures, as the previous example de- monstrated. In fact, altered chords in general were the starting point of this development, althoug they were not uncommon - we can even find the exact elements of the Tristan-chord in Wolfgang Amadeus Mozart's Stringquartet Eflat-major KWV 428 in the second movement, measures 18 and 19 (Amon, 200). But during these days, the composer was quite reluctant about re-interpreting those complex structures and preferred not to leave the universe of tonality and rather stayed on the ground. The first official textbook, which announced this prospect of ambigious chords and their re-evalutation was Arnold Schönbergs book Harmonielehre. Known as the father of the Second Viennese School, many people today forget about his intellectual input for music theory. It was Schönberg, who first investigated complex altered chords and found a name for their ambigious nature: Vagierende Akkorde. Nevertheless, Harmonielehre is no manifest for a new theory of avantgarde, but a textbook for the proper harmony teaching student with all dogmatic resolutions and procedures, which scholars used to teach for centuries - except the last part, where he gives a perspective of the future of complex chords. Concerning the modern chord structures, which can be found particulary in the works of Richard Wagner, Schönberg says: "Later, the student will be able to see the vagierenden Akkorde for what they really are, without tracing them back to a root or a function: homeless creatures, between the areas of the keys with a tremendous ability for adaption without independence; spies, looking for weaknesses to create diffusion; deserters, with the purpose to abandon their own personality; troublemakers in any sense, but even more: exhilarating companions" (Schönberg, 1966). In other words, we are talking about a rebellion against the system of functional tonality but at the same time about enrichment for our musical material. It is a fundamental task for the scholar to see such chords beyond the boundaries of their roots, since their true harmonic power has nothing to do with this hierarchy according to Schönberg: "If we refrain from explaining the true roots of the chords, their effect will be much clearer for us.

We will understand then that such chords don't necessarily have to appear in the function they are originally related to, because that climate of their descent has no influence on their true character (which is also the case with many other chords, as we will see)." The last part of this quote may underline Schönberg's 
tendency to throw over the complete constructional base of functional harmony, but from today's theory teaching methods we know that he was right about the ambigous chords: Modulation as the art from getting from one key to another has established besides the method of direct reinterpretation through equal chords of different degrees, also reinterpretation through enharmonic equivalent, especially with an augmented chord on the secondary dominant and the diminished seventh-chord, which has become a classic of modern modulation procedure (Schönberg, 1966). These two examples of Vagierende Akkorde show, how their ambivalent nature can become useful for tonal composing. But as Schönberg mentioned as well, to discover their true value, we have to leave the gravity of root-harmony and change to a different perspective: „Because the control of a progression in such a case through observation of scale degrees and roots is difficult to handle, the student may try to control the melodic perspective instead." In this phrase, Schönberg pronounces one of the most important changes of perspective in the history of music, from harmonic paradigm to melody.

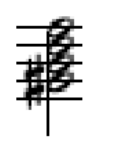

Diminished 7th-chord on the VII. degree of A-major

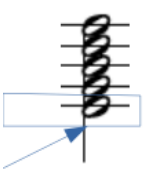

Re-evaluation as a shortened E-Major chord with 7th and 9th as V. degree / dominant of A-Major

Figure 4. Reinterpretation of complex chords.

\section{Analysis 4: Paul Hindemith and his cen- ter tone-theory}

In contemporary music, many people found different ways to establish new theories and methods of composing. However, one observation which they all shared was the insight that the material of functional harmony was too limited for a further development and had to be left - or altered. Schönberg's method was to completely abandon any temptation of hierarchy in tonal structure like the fundamental bass-theory has executed for many centuries. This well known equality led to the twelve tone system and certain harmonic liberty, which was not shared by everybody at the time. One of the most famous opponents of this atonality was German composer and scholar Paul Hin- demith. Instead of throwing away any kind of structural tonality, Hindemith suggested to keep a structure in music but based on a different level. Also for him, the functional scale degrees where not capable anymore to deliver the answer. Moreover, according to Hindemith they were just inaccurate, because they never considered an acoustic phenomenon of great importance: harmonic series. Concerning this phenomenon discovered by Pythagoras with his famous monochord-experiment and theoretically described by Jean-Baptiste Fournier in 1801, tones are related to a fundamental according to their frequency. For Hindemith, this should be considered as the real point of reference: In the intervall of a fourth from $g$ to $c$, the $c$ is the real fundamental tone, because $g$ is the sixth harmonic in the overtone row based on c. He also analyzed a range of different intervals according to their melodic and harmonic power: The third, as the old construction base of chords, is the one with the biggest harmonic power and the major second the one with the strongest melodic power. With this arsenal of new analyzed intervals, Hindemith constructs chords, which are not anymore based on the third-construction, but consist of many intervals like fourths, fifths or even seconds. The chord-structure is then based on the overtonebasis of the best interval. Each chord is then cathegorized into 2 groups regarding their interval-constitution: with tritone or without. This results into a strict control of harmonic gradient. We can see, that Hindemith's center tone-theory freed music of scale degrees but installed a new form of hierarchy, which is not completely distant from major/minor-tonality. This new approach of music as an alteration can be seen as a challenge of the fundamental bass-theory with its thirds-layering. What in fact Hindemith really wanted to avoid with this concept, was the phenomenon Schönberg and Wagner were so aware of: ambigious chords and especially their inversions (Hindemith, 1984).

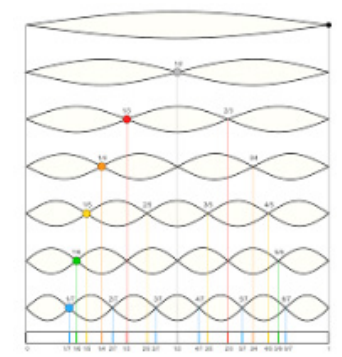

Figure 5. Harmonic series-frequencies 


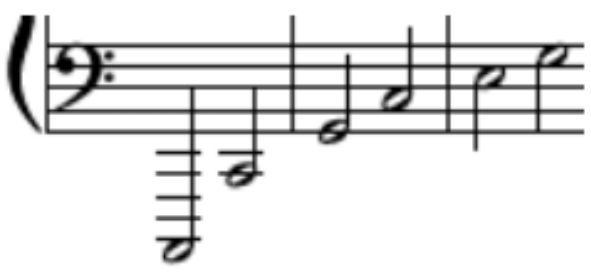

Figure 6. First six notes of the overtone row based on $\mathrm{C}$

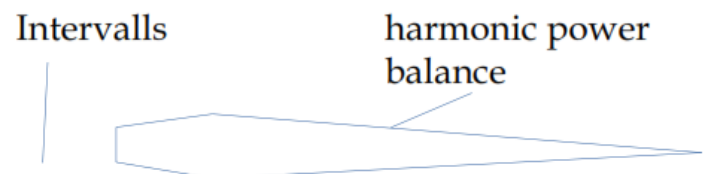

P8 P5 P4 M3 m6 M6 M2 m7 M2 m7 m2 M7

melodic power balance

Figure 7. Paul Hindemith's analysis of interval qualities.

The center tone theory shows, how complex and different the situation of music theory has become during contemporary composition. However, the examples until now were restricted to the field of harmony and tonal structure. What follows next, will excel every attempt of restoration of music and is still causing debates among artists and scholars.

\section{Analysis 5: Process instead of form}

The development we could see until now can be discribed as a form of individualism. Refinement of the material through the desertion of functional tonality and exploitation of chromaticism, have been methods to get away from a dogmatic universal language that operates through defined procedures, as we could see in the example of the four-part writing (Kühn, 2007). Schönberg's chord evaluation and Hindemiths center tone-theory have been ways to find new timbres in music beyond the borders of major and minor. Hindemith was one of the few scholars in his time, who were reluctand to take the last step and free music completely from its hierarchy and instead tried to find a compromise with an acoustic reference. These proceses of individualization, which led to individual systems, were about to be taken further up to one of the most radical steps in art history: the renounce of musical form. Shift in harmonic reference or abandon of tonality may be one aspect of musical revolution, but the distancing from form can be seen as the most drastic measure in the process of individualization. However, this technique is not easy to summarize, since there is a certain difference in the degrees of formal freedom in most concepts.

One of these possibilities is the oportunity for the performer to choose the beginning of a piece, which is written down and to continue from this point on as dictated by the sheet music. This is the case in Karlheinz Stockhausen's Klavierstück XI and what I call macroscopic openness. Another way is to choose from different elements the way they are put together - then the procedure from start to end has to be as given by the composer. Henry Pousseur used in Scambi a setting of tape excerpts, which segments could be put together individually and then had to be played in a given order. The interesting part of this microscopic openness is, that through every performance, the structural basis of the piece is reinvented every time. Through this method, especially Scambi has initiated a research project, to collect the executed performances in the past and the individual microstructure, which is related to each of them.

The third version of formal openness, is the maybe most popular one: Aleatoric. This term, strongly connected with the name of American composer John Cage, means in the first place the incorporation of coincidence. While macroscopic and microscopic openness offered some degree of specifiction, aleatoric composition seems to bring the process of musical individualization to a climax and is open on the macro- and microscopic level. For instance, Mauricio Kagel's prima vista offers a slide show of symbols, which demand "acoustic events" and are free in their sequence. What has developed into a variable form through freedom in some performance-aspects, is now a musical impetus, that is almost completely detached from any formal manifestation and leaves even more freedom to the performer. It is very important to mention these aspects of formal openness in context with the development of individualization, which implies the refusal of formal structures and tends to be in formal apparition more fluid than crystalline. This is why the term process becomes almost a surrogate for the term form and which is why Italian philosopher Umberto Eco used the term opera in movimento for this phenomenon in his publication Opera aperta (Eco, 1977). 


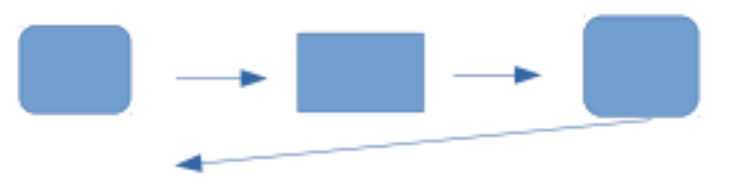

a) set of elements, choice of entry

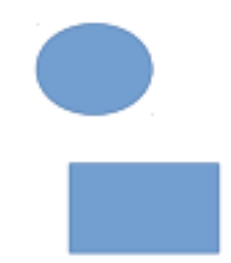

A B_ $C$

\section{b) choice of elementary setting}

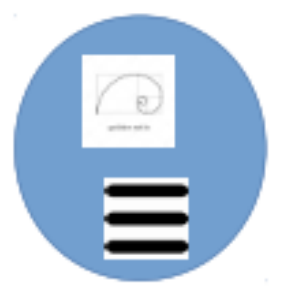

\section{c) free objects as sound-depiction}

Figure 8. Three models of formal opennes: macroscopic openness, microscopic openness and aleatoric form

\section{CONCLUSIONS}

The three models of contemporary theory in composing have shown one common demoninator: classic music theory with tonality as the universal gravity has left the stage and therefore new individual systems have arrived that gradually left the old hierarchic structure and even musical form at the end behind. What implications does that have for music theory? On the one hand, this means that it has become more difficult to analyze music by classical means, such as for instance reductionanalysis founded by Heinrich Schenker or the functional-theory from Hugo Riemann. Some new theories like Hindemith's center tonetheory have only a limited scope for his own compositions while others, like Schönberg's dodecaphony or aleatoric forms, have a more broader application in the history of contemporary music. For music theory this means trying to keep up with individual systems and understanding them, without falling back to the classical schemes of analysis but at the same time to execute with clarity and focus. Even if contemporary composing has become a kaleidoscope of different theories and techniques, analysis should be able to give a definite result in observing and even interpreting structures, even with the ability to postulate legilities, but of course valid only for a limited area. On the other hand, in order to do this, music theory has to invent new models and schemes to discribe the new compositions and try to extract the structures which are contained in the artworks. It is the task for the future to act like the scholars in the past such as Rameau and Schenker did and to find out the underlying layers in the most complex and individual works music history has ever seen.

\section{REFERENCES}

Amon R. (2005). Lexikon der Harmonielehre, Vienna/Munich:

Ludwig Doblinger KG, 41-310

Eco U. (1977). Das offene Kunstwerk, Frankfurt am Main: Suhrkamp, 27

Dack J. et al. The 'Scambi' Project, Open Forms and Electroacoustic Music, Middlesex University London, http:/ / www.scambi.mdx.ac.uk Kühn, C. (2007). Formenlehre, Kassel:

Bärenreiter, 204-205

Hindemith, P. (1940). Unterweisung im Tonsatz, I. Theoretischer Teil, Mainz: Schott, 1139-448

Rameau, J.P. (1722). Traité de l'Harmonie, Bourge La Reine: Zurfluh Editeur

Schönberg, A. (1966). Harmonielehre, Vienna: universal edition, 309-310

Moore C. et al. (2013). The Majesty of Music + Math, Santa Fe Institute, Santa Fe Symphony,

http:/ / tuvalu.santafe.edu/projects/musicplusmath/index.php?id=2 